\title{
SARS-CoV-2 infects brain choroid plexus and disrupts the blood-CSF-barrier
}

\author{
Laura Pellegrini ${ }^{1}$, Anna Albecka ${ }^{1}$, Donna L. Mallery ${ }^{1}$, Max J. Kellner ${ }^{1}$, David Paul ${ }^{1}$, Andrew P. Carter ${ }^{1}$, Leo C. James ${ }^{1}$, \\ Madeline A. Lancaster ${ }^{1 *}$
}

${ }^{1}$ MRC Laboratory of Molecular Biology, Francis Crick Avenue, Cambridge, CB2 0QH, UK.

*Correspondence to: MA Lancaster madeline.lancaster@mrc-lmb.cam.ac.uk

\begin{abstract}
Coronavirus disease-19 (COVID-19), caused by the SARS-CoV-2 virus, leads primarily to respiratory symptoms that can be fatal, particularly in at risk individuals. However, neurological symptoms have also been observed in patients, including headache, seizures, stroke, and fatigue. The cause of these complications is not yet known, and whether they are due to a direct infection of neural cells, such as neurons and astrocytes, or through indirect effects on supportive brain cells, is unknown. Here, we use brain organoids to examine SARS-CoV-2 neurotropism. We examine expression of the key viral receptor ACE2 in single-cell RNA sequencing (scRNA-seq) revealing that only a subset of choroid plexus cells but not neurons or neural progenitors express this entry factor. We then challenge organoids with both SARS-CoV-2 spike protein pseudovirus and live virus to demonstrate high viral tropism for choroid plexus epithelial cells but not stromal cells, and little to no infection of neurons or glia. We find that infected cells of the choroid plexus are an apolipoprotein and ACE2 expressing subset of epithelial barrier cells. Finally, we show that infection with live SARS-CoV-2 leads to barrier breakdown of the choroid plexus. These findings suggest that neurological complications may result from effects on the choroid plexus, an important barrier that normally prevents entry of immune cells and cytokines into the cerebrospinal fluid (CSF) and brain.
\end{abstract}

Keywords: COVID-19, neurotropism, choroid plexus, SARS-CoV-2, organoids, cerebrospinal fluid, CNS barrier

\section{Introduction}

The COVID-19 global pandemic caused by the Severe Acute Respiratory Syndrome Coronavirus 2 (SARS-CoV-2) has infected more than 20 million people and caused around 740,000 deaths as of early August 2020 (worldometers.info/coronavirus) and it still poses a constant threat to public health systems worldwide. Respiratory symptoms, predominantly associated with the infection, include fever, chest tightness and persistent cough (Wu et al., 2020).

SARS-CoV-2 shares around $80 \%$ sequence similarity with SARS-CoV (Wang et al., 2020) and both use their spike (S) glycoprotein to mediate host cell entry (Wang et al., 2020; Wu et al., 2020). SARSCoV-2 enters the cells using a cell surface receptor, angiotensinconverting enzyme 2 (ACE2) (Hoffmann et al., 2020b, 2020a). Coentry factors such as TMPRSS2 (Hoffmann et al., 2020a), TMPRSS4 (Zang et al., 2020) and neuropilin1 (Cantuti-Castelvetri et al., 2020; Daly et al., 2020) have also been reported to potentiate infectivity. CoVs are widely believed to enter the cells via two mechanisms: via the endocytic pathway and via a non-endosomal pathway (Ou et al., 2020; Yang and Shen, 2020). Direct fusion of the virus to the plasma membrane seems to be the predominant route of entry of SARS-CoV-2 (Hoffmann et al., 2020b). SARS-CoV-2 and SARS-CoV both use their S protein, composed of two subunits S1 and S2, for viral entry: S1 facilitates viral attachment to the receptor ACE2 and S2 is essential for membrane fusion, which also involves the host cell protease TMPRSS2 (Hoffmann et al., 2020b, 2020a; Walls et al., 2020; Wrapp et al., 2020).

The overwhelming majority of respiratory symptoms suggest that the first target for viral entry is the respiratory tract (Sungnak et al.,
2020). Recent RNA-sequencing data from multiple tissues from healthy human donors reported viral tropism for nasal epithelial cells, predominantly ciliated cells and goblet cells, highly secretory cells involved in mucus secretion, expressing viral entry-associated genes including ACE2 and TMPRSS2 (Sungnak et al., 2020). Expression of these viral entry genes has also been reported to promote viral entry in human small intestine enterocytes (Zang et al., 2020), suggesting potential viral spread through the fecal-oral route and explaining the common gastrointestinal symptoms observed in patients. These findings have been corroborated by experiments conducted in human intestinal organoids, which show high expression of SARS-CoV-2 entry factors and infection of human enterocytes with both SARS-CoV and SARS-CoV-2 (Lamers et al., 2020). Enterocytes are highly secretory cells which express ACE2 and produce large lipid vesicles containing lipoproteins involved in the generation of chylomicrons, trygliceride-rich lipoprotein particles important for systemic lipid transfer (Ko et al., 2020).

Even though respiratory systems seem to be the most affected, increasing evidence from clinical reports indicates a rise in both acute and chronic neurological symptoms including sudden and complete loss of smell, headache, seizures, stroke and long-term clinical complications such as persistent fatigue (Montalvan et al., 2020) and meningitis/encephalitis (Moriguchi et al., 2020). These symptoms suggest viral tropism for brain cells; however, which cell types remains to be fully determined. Furthermore, while preliminary reports using in vitro systems, including neural organoids, suggest some neurotropism, the physiological relevance is still unclear. In particular, the degree of infection relative to more susceptible cell types, as well as the route of entry in to the brain, remains to be explored. 
Interestingly, one case reported SARS-CoV-2 in the cerebrospinal fluid (CSF) but not in the nasopharyngeal specimen collected from a patient presenting neurological symptoms (Moriguchi et al., 2020). Dissemination through the central nervous system (CNS), however, has not yet been demonstrated, and viral presence in brain tissue and CSF has not been widely reported. Nonetheless, viral entry through the olfactory bulb and cribriform plate have been suggested as potential routes of entry to the CNS (Montalvan et al., 2020). Other possible routes of entry of virus or bacteria into the brain are through the blood-CNS barriers such as the blood-brainbarrier (BBB) or the blood-CSF-barrier (B-CSF-B). The BBB, which separates the systemic blood from the brain parenchyma, is a complex barrier constituted by multiple cells types and mainly formed by the tight junctions between endothelial cells. The B-CSF$B$ is formed by the epithelial cells of the choroid plexus (ChP) and separates the blood from the cerebrospinal fluid (CSF) (Ghersi-Egea et al., 2018; Lehtinen et al., 2011; Lun et al., 2015a; Strazielle and Ghersi-Egea, 2013). The ChP also produces the CSF, a colourless fluid that provides essential nutrients and helps clear out waste byproducts (Dani et al., 2019; Fame and Lehtinen, 2020; Ghersi-Egea et al., 2018; Lehtinen and Walsh, 2011; Lehtinen et al., 2011; Lun et al., 2015b). CSF is produced by filtering blood from a dense network of fenestrated capillaries that lie within the stroma. The stroma is a rich environment that also provides a site of immune surveillance. But it is the epithelial cell layer of the ChP that forms the tight barrier and prevents entry of pathogens and toxic substances into the CSF (Lun et al., 2015a), as well as acting as a gateway for immune cells (Schwerk et al., 2015).

Because human brain tissue is difficult to access for the purpose of functional studies, including the investigation of viral tropism, recent studies have made use of $3 D$ in vitro models called cerebral organoids to examine infection, for example with Zika virus (Qian et al., 2017; Zhou et al., 2017). These tissues can faithfully recapitulate, on a cellular-architecture and on a gene expression level, the early stages of brain development and can form mature neurons organised in thick axon tracts when cultured at the airliquid interface (Giandomenico et al., 2019; Lancaster et al., 2017). We recently developed a cerebral organoid model to study the ChP (Pellegrini et al., 2020), which recapitulates the epithelial polarisation of ChP cells and the formation of a tight barrier which separates the surrounding media from the CSF-like fluid secreted by the ChP (Lancaster et al., 2017, 2013). To test viral tropism of SARS-CoV-2 in various cells of the CNS, we examined the expression patterns of viral entry factors in cerebral and ChP organoids, and tested for infection with both pseudovirions carrying SARS-CoV-2 spike, and live SARS-CoV-2. We found that ChP expressed SARSCoV-2 entry factors in a previously unidentified lipoproteinproducing population of cells and that SARS-CoV-2 spike pseudovirions and live virus can productively infect ChP epithelial cells. In contrast, neurons and other CNS cell types were not generally susceptible, except under extreme infection with large viral quantities. We observed that the primary effect of the virus was on ChP cells, which disrupted integrity of this key CNS barrier.

\section{Results}

ACE2 and other entry factors are expressed in the choroid plexus

To assess whether SARS-CoV-2 entry factors are present in various cell types in organoids, we looked at the expression of the receptor ACE2 and the co-entry factor TMPRSS2 in different clusters of cells from previously published scRNA-seq data from $\mathrm{ChP}$ and telencephalic organoids (Pellegrini et al., 2020) (Fig. 1A, Fig. S1A). Expression of ACE2 and TMPRSS2 was detected predominantly in the immature $\mathrm{ChP} /$ hem cluster, and mature $\mathrm{ChP}$ clusters, but not in the neural progenitor or neuron clusters. ACE2 was also detected, although to a lesser extent in the ChP stroma (Fig. 1A, Fig. S1A). To examine whether these results are in agreement with the expression in vivo, we analysed data from the Allen Brain Atlas (Hawrylycz et al., 2012; Miller et al., 2017) reporting expression levels of ACE2 in different human brain regions (Fig. 1B). Among all the different brain regions compared, we found highest levels of ACE2 in the ChP (Fig. $1 B)$, validating our findings in vitro.

To better characterise the distribution of SARS-CoV-2 entry factors in the different ChP populations, we performed sub-clustering of all the ChP cell populations and we identified four prominent clusters: immature $\mathrm{ChP}$, mature $\mathrm{ChP}$, hem and $\mathrm{ChP}$ stroma, as well as two smaller clusters, one that appeared to be neural crest cells, and one that was enriched in expression of lipoprotein genes, suggesting a function in lipid-production and transfer (Fig. 1C). We then looked at A
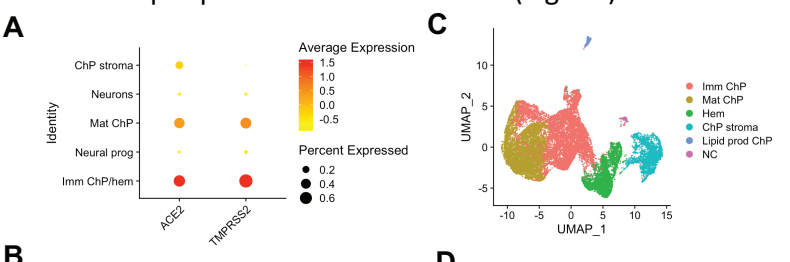

B

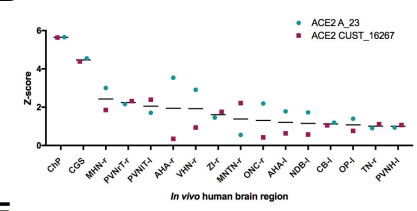

D

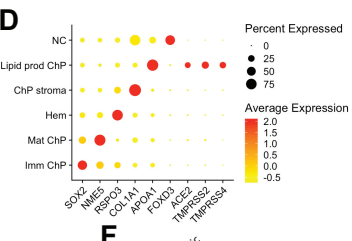

E
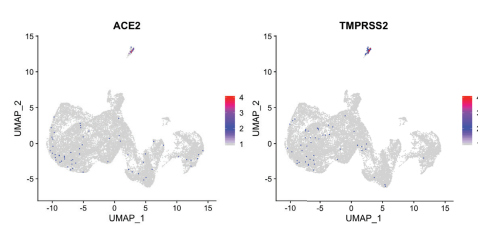

F

G

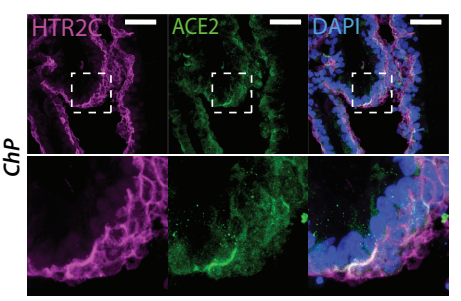

H
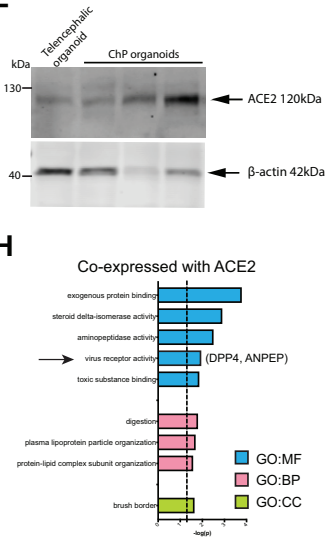

Figure 1. ACE2 and other entry factors are expressed in the choroid plexus

(A) Dot plot showing average expression and percentage of cells expressing SARS-CoV-2 entry factors ACE2 and TMRPSS2 in the five main clusters identified by scRNA-seq of ChP and telencephalic organoids (Pellegrini et al., 2020). (B) Allen Brain Atlas expression data of ACE2 (probe names: ACE2 A_23 and ACE2 CUST_16267) in different human brain regions, with highest expression in the ChP. Regions with an average z-score across the two probes (black line) of greater than 1 are shown. (C) UMAP plot showing subclustering of all ChP cell types identified by scRNA-seq. Imm $\mathrm{ChP}=$ immature $\mathrm{ChP}$; Mat $\mathrm{ChP}=$ mature $\mathrm{ChP}$, Lipid prod $\mathrm{ChP}=$ lipid producing $\mathrm{ChP}, \mathrm{NC}=$ neural crest. (D) Dot plot showing average expression and percentage of cells for key marker genes present in the subclusters identified by scRNA-seq. Lipidproducing $\mathrm{ChP}$ express SARS-CoV-2 entry genes ACE2, TMPRSS2 and TMPRSS4. (E) Feature plots showing expression of ACE2 and TMPRSS2 in the subpopulations identified by scRNAseq. (F) Immunoblot for ACE2 and the loading control $\beta$-actin of $\mathrm{ChP}$ and telencephalic organoid protein lysates. (G) Representative confocal images of $\mathrm{ChP}$ tissue immunostained for the ChP epithelial marker HTR2C (serotonin receptor 2C) in magenta and ACE2 in green. Nuclei in blue are stained with DAPI. Scale bar: $50 \mu \mathrm{m}$. (H) gProfileR (Reimand et al., 2011) analysis of genes co-expressed with ACE2 showing significant enrichment $(p<0.05)$ for GO categories cellular component (GO:CC), molecular function (GO:MF) and biological process (GO:BP). 
the main SARS-CoV-2 entry genes in these cell populations and found expression of entry factors ACE2, TMPRSS2 and TMPRSS4 in the lipoprotein-expressing cells in the ChP, which express genes involved in lipid metabolism such as APOA1 and APOA2 (Besler et al., 2012; Wang et al., 2019) (Fig. 1D-E, Fig. S1B). Next, we validated ACE2 expression by immunoblot comparing telencephalic organoids with ChP organoids (Fig. 1F). We could detect ACE2 in ChP organoid lysates and, to a lesser extent in telencephalic organoids, which would also be expected to contain some telencephalic ChP (Fig. 1F). Next, to better compare expression of ACE2 in both neuronal and ChP tissue simultaneously, we performed immunostaining of organoids containing cortical (Fig. S1C) or ChP identities (Fig. 1G). Consistent with the scRNA-seq data, the ChP epithelial tissue, marked by the serotonin receptor HTR2C, showed sparse but strong positive signal for ACE2 compared to cortex. Together, these findings indicate that ACE2 is expressed in cells of the ChP, but no specific expression of ACE2 is present in neuronal progenitors or neurons. Expression of TMPRSS2 was also detected by immunostaining in the membrane of ChP epithelial cells from organoids (Fig. S1D).

To further explore the expression profile of these identified ACE2 expressing ChP cells, we investigated which genes showed correlated expression pattern with ACE2. Gene Ontology Analysis of genes coexpressed with ACE2 revealed enrichment in GO:MF categories "exogenous protein binding", "viral receptor activity", "toxic substance binding" and "aminopeptidase activity"; GO:BP category "protein-lipid complex subunit organization" and GO:CC category "brush border" (Fig. 1H). We found enriched expression of DPP4 (dipeptidyl peptidase 4) and ANPEP (alanyl aminopeptidase), which both encode for known receptors of human CoVs (Qi et al., 2020), and were similarly enriched in the lipoprotein producing subcluster, but not in neurons or other cell types (Fig. S1E, Fig. S1F). In particular, DPP4 is the receptor for MERS-CoV, whereas ANPEP is a receptor for human coronavirus 229E, among other human CoVs (Qi et al., 2020). Interestingly, ChP cells of this subcluster also express lipoproteins that are also required for assembly of hepatitis $C$ virus (HCV), as well as some HCV entry factors such as SCARB1 and CD81 (Aizawa et al., 2015; Grassi et al., 2016; Wrensch et al., 2018) (Fig. S1G). Together these data suggest that: 1 . ChP cells and, specifically, lipoprotein-expressing ChP cells, express entry factors required for SARS-CoV-2 infection and 2. Neuronal progenitors and neurons do not specifically express SARS-CoV-2 entry factors.

SARS-CoV-2 spike pseudovirus only infects ChP cells of brain
organoids

To examine SARS-CoV-2 neurotropism, we incubated brain organoids with mixed identities including ChP and cortical tissue with SARSCoV-2 spike pseudovirions carrying a 19 amino acid deletion (c19) from the C-terminus, which allows for better expression and integration of the spike into the lentivirus (Giroglou et al., 2004; Ou et al., 2020). Spike pseudovirions allow investigation of viral entry without other effects of live CoV such as cell death or viral replication, and because they encoded for GFP we could visualise infected cells only (Giroglou et al., 2004). As a negative control, pseudovirions lacking viral envelope glycoprotein ( $\Delta$ env) were used for the infection. VSV-G pseudotyped lentivirus (VSV) with broad viral tropism was used as a positive control (Fig. S2A-C). A biochemical assay of the viral reverse transcriptase (RT) was used to assess viral particle production and subsequent titration in ACE2 overexpressing
A

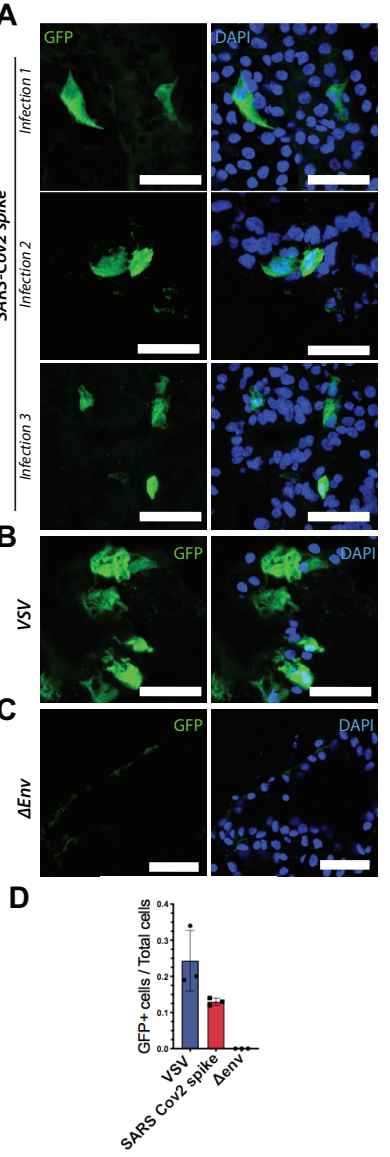

E

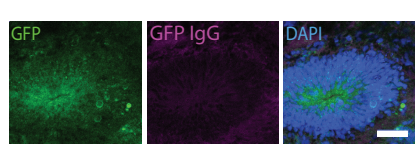

$\mathbf{F}$

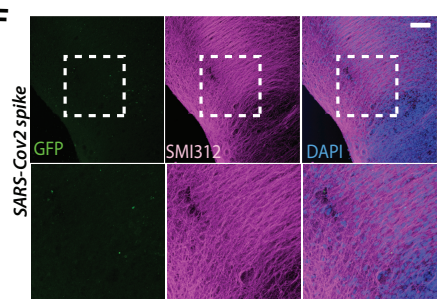

$\mathbf{G}$

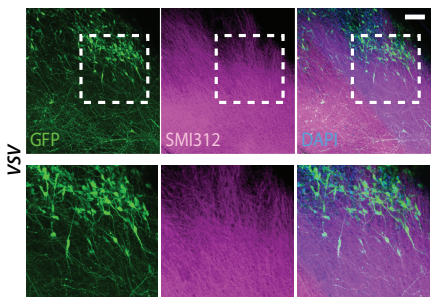

H

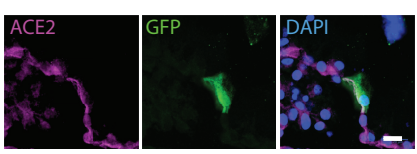

Figure 2. SARS-CoV-2 spike pseudovirus infects ChP cells but not other brain cells of cerebral organoids

(A) Representative confocal images of $\mathrm{ChP}$ epithelial tissue from organoids infected SARS-CoV2 spike pseudovirions. GFP positive cells, as detected by GFP antibody, are shown from three independent experiments. Nuclei in blue are stained with DAPI. Scale bar: $50 \mu \mathrm{m}$. (B) Representative confocal images of $\mathrm{ChP}$ epithelial tissue from organoids infected with VSV-G lentivirus. Scale bar: $50 \mu \mathrm{m}$. (C) Representative confocal images of ChP epithelial tissue from organoids infected with lentivirus pseudovirions lacking viral glycoprotein of the envelope ( $\Delta$ env). Scale bar: $50 \mu \mathrm{m}$. (D) Quantification of GFP-positive cells over total counted cells for VSV-G, SARS-CoV-2 spike and $\Delta$ env lentiviral infected ChP epithelial cells from organoids. ( $\mathrm{n}=100$ cells counted for each of the three independent experimental repeats). (E) Representative confocal image of a cortical lobe of a cerebral organoid infected with spike pseudovirions showing an example of a false positive signal due to GFP autofluorescence and stained with antiGFP antibody (in magenta). Nuclei in blue are stained with DAPI. Scale bar: $50 \mu \mathrm{m}$. (F) Representative images of ALI-CO infected with spike pseudovirions and immunostained with axonal marker SMI312 in magenta, anti-GFP antibody in green, and DAPI in blue. Scale bar: $100 \mu \mathrm{m}$. (G) Representative images of ALI-CO infected with VSV lentivirus and immunostained with axonal marker SMI312 in magenta, anti-GFP antibody in green, and DAPI in blue. Scale bar: $100 \mu \mathrm{m}$. (H) Higher magnification image of $\mathrm{ChP}$ epithelial tissue from organoids immunostained for ACE2 in magenta, GFP and DAPI. Scale bar: $20 \mu \mathrm{m}$.

293T cells (Fig. S2A-C). We initially examined infection by direct observation of GFP fluorescence (Fig. S2D), which clearly showed positive cells, but also some putative autofluorescence in the green channel. Indeed, we found that dead or dying cells displayed quite bright fluorescence in the same channel as GFP (Fig. S2E). Therefore, to be sure we were observing true GFP signal from infected cells, we added a step of immunostaining with a GFP antibody, which allowed for accurate assignment of infected cells.

We performed three independent infections with SARS-CoV-2 spike pseudovirions of organoids, which revealed viral tropism for ChP epithelial tissue, as indicated by the GFP antibody-positive signal (Fig. 2A). Positive control for the infection with VSV lentivirus confirmed a broader tropism (Fig. 2B, Fig. S2F), whereas no positive signal was detectable in organoids infected with $\Delta$ env lentivirus (Fig. 2C, Fig. 
A

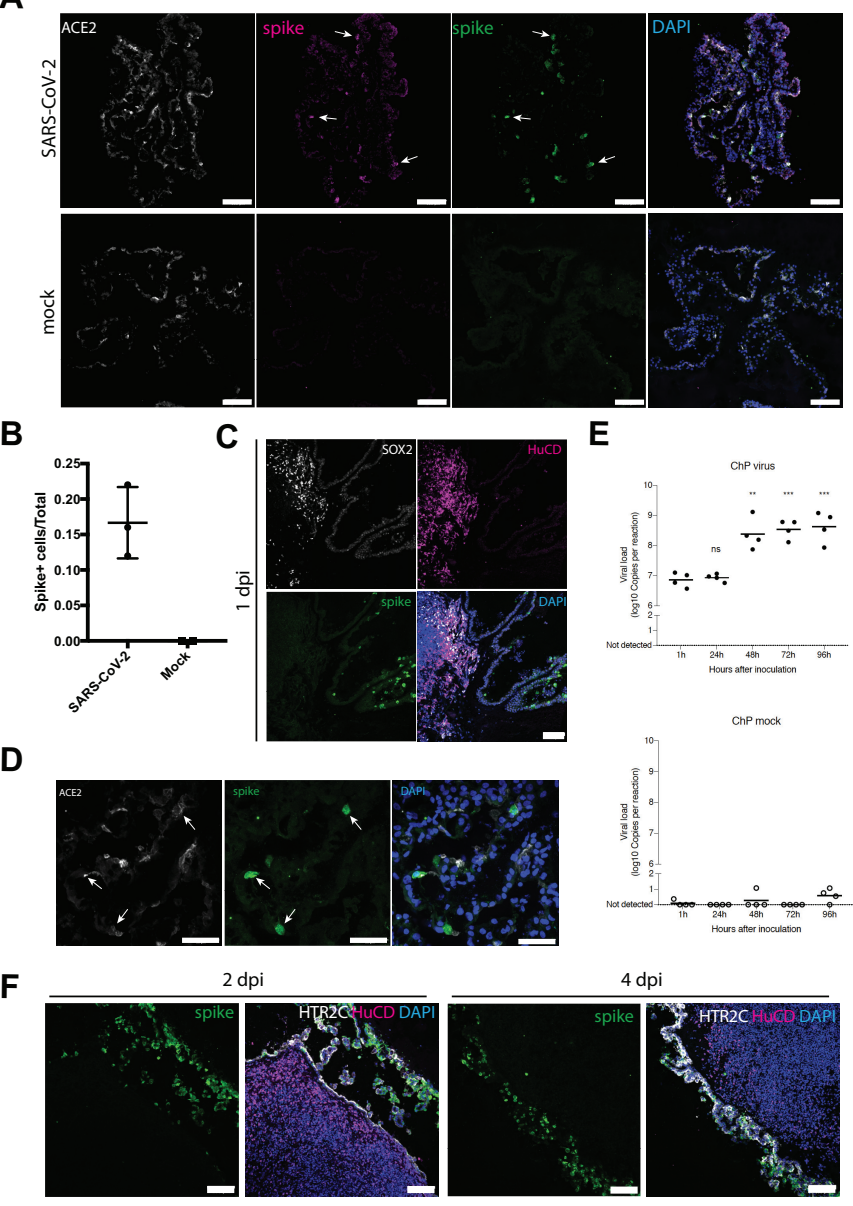

Figure 3. Live SARS-CoV-2 productively infects ChP epithelium

(A) 1 day post-infection of $\mathrm{ChP}$ organoids with either live SARS-CoV-2 or mock and staining for two independent antibodies (Abcam ab252690 spike glycoprotein in magenta and GeneTex GTX632604 in green) directed to the viral spike protein. Specific staining (arrows) is only seen in the SARS-CoV-2 infection condition. Scale bars: $100 \mu \mathrm{m}$. (B) Quantification of infected cells staining positive for viral spike protein in ChP tissue infected with SARS-CoV-2 ( $n=3$ independent infections) compared with mock ( $\mathrm{n}=2$ independent infections). (C) Staining for viral spike protein in mixed identity telencephalic organoids at 1 day post-infection (dpi) showing staining only in ChP tissue. Scale bar: $100 \mu \mathrm{m}$. (D) Co-staining for ACE2 in infected cells of ChP tissue (arrows). Scale bars: $50 \mu \mathrm{m}$. (E) RT-qPCR using primers and probes against the CDC $\mathrm{N} 1$ amplicon of SARS-CoV-2 in infected and mock over the course of 4 days post-infection. $\mathrm{n}=4$ organoids from 2 independent infections. ${ }^{* * P} P=0.002, * * * P<0.001$, Two-tailed unpaired Student's $t$-test. (F) Staining for viral spike protein in mixed identity telencephalic organoids displaying adjacent cortical and $\mathrm{ChP}$ tissues at 2 days post-infection and 4 days post-infection. Scale bars: $100 \mu \mathrm{m}$

S2F). Quantification of the ratio of GFP-positive cells to total cells showed that spike pseudovirions infected around $13 \%$ of cells in the ChP epithelium (Fig. 2D).

Interestingly, we found that neuronal regions of organoids with mixed identity did not seem to get infected with the virus (Fig. S2G), and the only signal we could detect in the green channel was autofluorescence (Fig. 2E, Fig. S2G). To further investigate the ability of spike pseudovirus to infect cortical tissue and neurons, we infected Air-Liquid Interphase Cerebral Organoids (ALI-COs) (Giandomenico et al., 2019), which are long-term cultures of organoids that lead to improved neuronal maturity and function. ALI$\mathrm{COs}$ infected with spike pseudoviruses and immunostained for SMI312 to visualise the neurons showed no specific GFP-positive signal (Fig. 2F), when compared to the signal detected in ALI-COs infected with the positive control (Fig. 2G). This indicated the lack of signal upon SARS-CoV-2 spike infection was not due to defective GFP expression, but rather a lack of viral entry.
These findings support the hypothesis that susceptibility to infection by SARS-CoV-2 in the brain is also governed by expression of ACE2, which is only present on ChP epithelial cells of the organoids. Further supporting this claim, confocal imaging of infected cells immunostained for ACE2 showed positive signal on the membrane of spike pseudoviruses infected ChP cells (Fig. 2H).

\section{Live SARS-CoV-2 productively infects ChP tissue}

Recent reports have similarly explored neurotropism of SARS-CoV-2 using brain organoids and neurospheres, but with contradictory findings to those we observed here (Ramani et al., 2020; Song et al., 2020). One possible explanation is the use of pseudovirus versus live SARS-CoV-2, with other reports making use of live viral isolates. Therefore, to explore this possibility we turned to infections with a live SARS-CoV-2 clinical isolate (Papa et al., 2020). We first infected ChP organoids with an equivalent amount of virus as we had performed using pseudovirions, and observed highly comparable infection (Fig. 3A, B). We next tested whether this same amount of virus was capable of infecting neurons and other cortical cells of telencephalic organoids with a mixed identity containing also ChP. We still found infection exclusively of the ChP in these conditions (Fig. 3C). Again, this infection matched ACE2 expression, with infected cells co-staining for the receptor (Fig. 3D) in the ChP epithelium, whereas stromal cells of the ChP were uninfected (Fig. S3).

We next examined whether ChP cells represent a permissive cell type for viral replication. We performed QRT-PCR for viral N1 and observed a significant increase in viral genome copies in organoid supernatant over the course of 4 days (Fig. 3E) with the largest increase between 1 and 2 days of infection. This matched staining where we similarly observed larger numbers of cells infected in the $\mathrm{ChP}$ at 2 and 4 days post-infection (Fig. 3F).

\section{SARS-CoV-2 has minimal tropism for neurons but disrupts barrier integrity of the ChP}

We next sought to test whether there could be any conditions in which neurons or other CNS cell types may be infected with SARSCoV-2. We did not observe any viral spreading from ChP to nearby cortical regions, even when in very close proximity and left for as long as 4 days (Fig. 3F). However, one possibility is that

the virus preferentially infects ChP resulting in lower amounts of viral particles available to infect the surrounding neurons. We therefore tested infection with live virus on "pure" cortical organoids containing no $\mathrm{ChP}$, but still saw no specific staining for viral protein in neurons or neural progenitors (Fig. 4A, Fig. S4A). Finally, we tested whether a combination of longer exposure and much higher viral quantities would lead to infection. We performed infection of ALICOs with 10 times the viral MOI used for ChP infection, and were able to observe very sparse, but specific, neuronal and glial infection after 2 days post-infection (Fig. 4B, Fig. S4B). This suggests that SARSCoV-2 has a much lower infectivity of human neural cell types compared with ChP epithelium. This finding was also consistent with the expression of markers of the lipoprotein-expressing cell type, which were present in cells infected by SARS-CoV-2 in the ChP epithelium (Fig. 4C, D), but absent from cortical neuronal regions (Fig. 4E). 
A

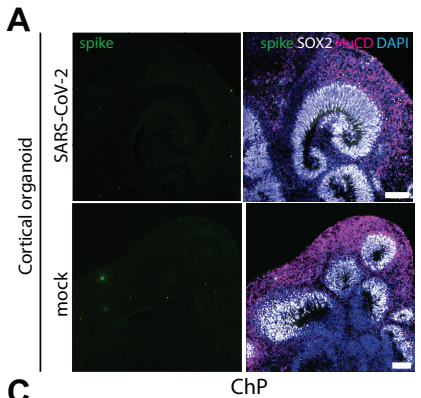

C

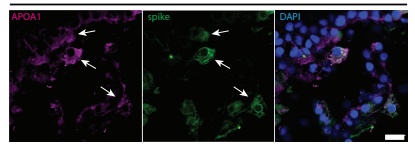

D

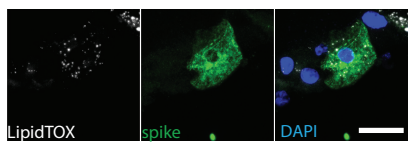

G
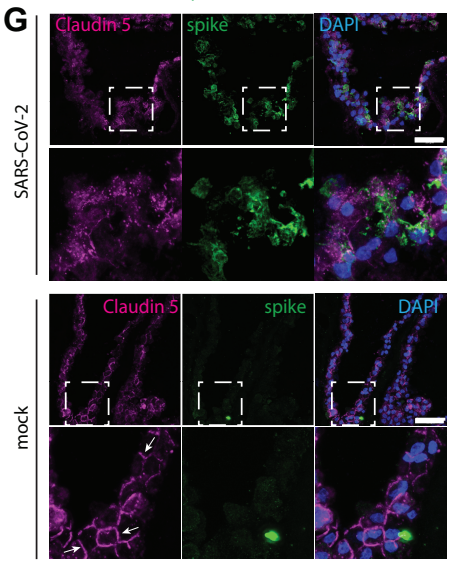

B
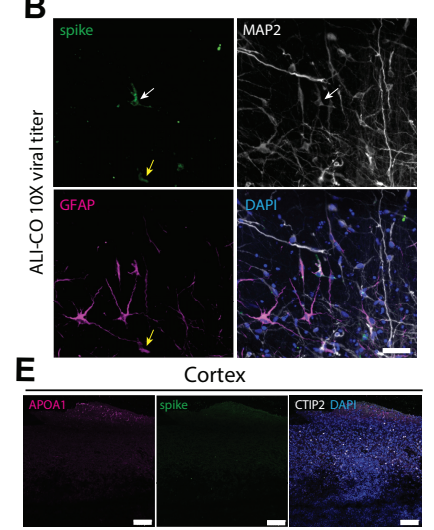

F

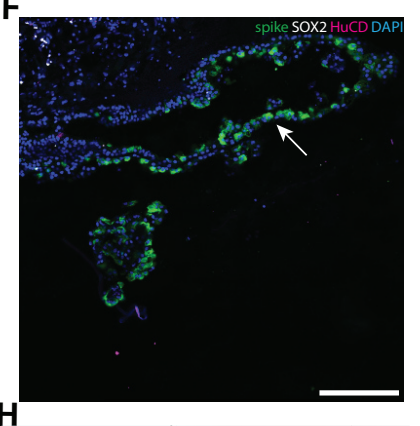

$\mathrm{H}^{-}$

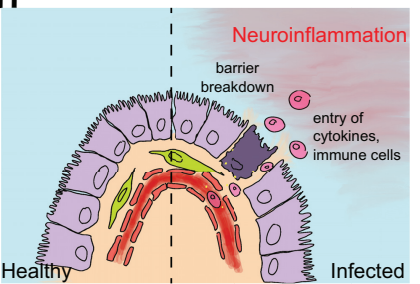

Figure 4. SARS-CoV-2 disrupts ChP epithelial integrity

(A) Staining for viral spike protein in pure cortical organoids infected with either SARSCoV-2 or mock showing no specific staining in either condition. Scale bars: $100 \mu \mathrm{m}$. (B) Staining for viral spike protein in ALI-COs infected for 2 days with 10 times the dose used for ChP or mixed identity organoids. Note sparse staining of a neuron (white arrow) that is positive for MAP2 and a glial cell (yellow arrow) that is positive for GFAP. Scale bars: $50 \mu \mathrm{m}$. (C) Co-staining for APOA1 and viral spike protein in ChP epithelium after 1 day post-infection. Scale bar: $20 \mu \mathrm{m}$. (D) Co-staining for LipidTOX and viral spike in a ChP epithelial cell after 1 day post-infection. Scale bars: $20 \mu \mathrm{m}$ (E) APOA1 staining in infected cortical tissue showing no viral spike staining and only sparse APOA1 outside the cortical neuronal region marked by CTIP2. Scale bars: $100 \mu \mathrm{m}$. (F) Staining for viral spike protein in telencephalic organoid with intact CSF-like fluid filled cyst (arrow) showing infection after application of virus on the basal (outer) surface. Scale bar: $200 \mu \mathrm{m}$. (G) Staining for tight-junction protein Claudin 5 in ChP epithelium infected with SARS-CoV-2 or mock at 2 days post-infection. Note the presence of clearly demarcated junctions (arrows) in mock versus infection with SARS-CoV-2. Green fluorescent signal in mock represents typical nonspecific background, which does not label a cell. Scale bars: $50 \mu \mathrm{m}$. (H) Model of the effect of SARS-CoV-2 infection of the $\mathrm{ChP}$ and the effect on CNS barrier integrity.

We next examined the impact of SARS-CoV-2 infection on the ChP epithelium. First, because the ChP epithelium is highly polarized with its basal side facing the endothelial compartment, potential viral entry in vivo would have to occur from the basal surface. We therefore tested whether SARS-CoV-2 could successfully infect the ChP epithelium from the basal, or media side, of intact tissues with clear, fluid-filled cysts. This experiment revealed abundant infection from the basal side (Fig. 4F), suggesting that blood-borne virus can indeed infect from the vascular compartment of the ChP. Second, because the ChP is an integral part of the blood-CNS barrier, we examined the effect of viral infection on barrier integrity. We observed a striking effect on cell-cell junctions (as labeled by Claudin5) after 2 days post-infection (Fig. 4G) and after 4 days the tissue was visibly damaged compared with mock (data not shown). Taken

together, these data suggest that SARS-CoV-2 is capable of infecting a subset of ChP epithelial cells, which leads to a breakdown of barrier integrity (Fig. 4H).

\section{Discussion}

Preliminary clinical reports on SARS-CoV-2 have highlighted neurological symptoms such as headache, encephalitis and nausea, suggesting a neuroinvasive potential of the virus (Montalvan et al., 2020; Moriguchi et al., 2020). It was unclear, however, whether SARS-CoV-2 can infect neuronal cells. Understanding viral tropism is of significant interest for the development of better treatments and for prevention of long-term adverse effects. Our findings indicate that SARS-CoV-2 does not readily infect neuronal cells, but rather infects ChP epithelial cells of the brain. This finding is consistent with the high levels of expression of SARS-CoV-2 entry factors such as ACE2 and TMPRSS2 in the ChP in vivo and in vitro, compared to other brain regions (Chen et al., 2020). Furthermore, our findings of susceptibility of a specific lipoprotein-producing cell type, matches closely the susceptibility seen in other organs such as the intestine (Lamers et al., 2020).

A likely interpretation of these results is that the neurological symptoms reported in COVID-19 patients are mainly due to an indirect, secondary consequence of viral infection of support cells in the brain, rather than neurons themselves. We show that infection of the ChP epithelium by SARS-CoV-2 leads to disruption of the BCSF-B. While this could then allow entry and spread of the virus into the brain, our results suggest that neural cells are minimally susceptible, even when exposed to high quantities of virus. Furthermore, substantial SARS-CoV-2 within the brain and CSF does not seem to be a widely reported finding (Schaller et al., 2020). Nonetheless, barrier breakdown could allow abnormal entry of immune cells and cytokines leading to harmful neuroinflammation (Fig. 4H).

It is known that immune cells, including macrophages, dendritic cells and monocytes, continuously survey the B-CSF-B, and infection of ChP epithelial cells can lead to pro-inflammatory cytokine production and recruitment of T-cells that can initiate neural tissue injury (Ransohoff and Engelhardt, 2012). Furthermore, the B-CSF-B might be a particularly vulnerable barrier to invasion of this sort because the tight junctions between cells have lower electrical resistance compared to the blood-brain-barrier (BBB) (Redzic, 2011; Schwerk et al., 2015). Finally, normal functioning of the ChP is necessary for proper CSF production and turnover, which is essential in providing nutrients and clearing metabolic waste. These roles have recently gained attention with the discovery of the so-called "glymphatic system", which seems to be most active during sleep when changes in CSF flow also occur (Fultz et al., 2019; Olsson et al., 2018).

It is interesting to note that among the neurological disturbances experienced in this and previous CoV outbreaks, chronic fatigue and nonrestorative sleep disturbances have been noted (Moldofsky and Patcai, 2011). Indeed, multiple viruses, such as HCV, HIV and EBV, have been linked to chronic fatigue syndrome (CFS), also known as myalgic encephalomyelitis (ME) (Payne et al., 2013; Rasa et al., 2018; Williams et al., 2019). In the case of HCV, the most common extrahepatic symptom in patients is chronic fatigue (Poynard et al., 2002). Key mediators of HCV assembly are apolipoproteins, and regulation of lipoprotein metabolism is important for the HCV 
replication cycle (Aizawa et al., 2015; Grassi et al., 2016). Lipoproteins are mainly synthesized by hepatocytes and intestinal cells (Aizawa et al., 2015); however, we report here a previously unrecognized lipoprotein-producing cell population in the $\mathrm{ChP}$ that also expresses viral entry factors for HCV and for SARS-CoV-2, perhaps explaining the particular susceptibility of this CNS tissue.

While the exact cause of CFS/ME is still obscure, abnormal levels of a number of cytokines, such as IL-10 have been observed in CSF from patients with CFS/ME (Natelson et al., 2005), suggesting an imbalance in neuroimmune modulation. This points to a potential breakdown or dysfunction of the B-CSF-B, allowing leakage of immune cells and cytokines into the brain. Alternatively, or perhaps in combination, the role of the ChP in CSF production and turnover could be compromised, thus leading to defects in waste clearance during sleep.

Together, these observations, combined with our results from human brain organoids, suggest the intriguing possibility that the ChP epithelium is particularly susceptible to infection by viruses, and that this susceptibility may lead to breakdown of the B-CSF-B and development of CFS/ME symptoms. In the case of SARS-CoV-2, this susceptibility seems to be dictated by the expression of ACE2, which is primarily expressed in ChP epithelium. Thus, our findings suggest that the neurological symptoms are not due to a direct effect on neurons, but rather a consequence to the damage of this important supportive tissue resulting in proinflammatory changes in the fluid it secretes.

\section{Materials and Methods}

\section{Cells and plasmids}

HEK 293T CRL-3216 cells were purchased from ATCC and authenticated by the supplier. All cells were regularly tested and were mycoplasma free. HEK 293T cells were maintained in Dulbecco's modified Eagle's medium (DMEM) with 10\% FBS, 2 mM Lglutamine, $100 \mathrm{U} / \mathrm{ml}$ penicillin, and $100 \mu \mathrm{g} / \mathrm{ml}$ streptomycin (Gibco) at $37^{\circ} \mathrm{C}$ with $5 \% \mathrm{CO} 2$. Vero cells were purchased from ATCC and maintained in DMEM supplemented with $10 \%$ FBS, $100 \mathrm{U} / \mathrm{ml}$ penicillin and $100 \mathrm{mg} / \mathrm{ml}$ streptomycin. Cells tested negative for mycoplasma before virus production and infection experiments. Vero-hACE2 were generated by transducing Vero cells with lentiviral particles expressing hACE2 ORF and cultured in DMEM 10\% FCS with $5 \mathrm{\mu g} / \mathrm{ml}$ blasticidin. Vero-hACE2-TMPRSS2 were generated by transducing Vero-hACE2 with lentiviral particles expressing TMPRSS2 ORF and maintained in DMEM $10 \%$ FCS with addition of $5 \mu \mathrm{g} / \mathrm{ml}$ blasticidin and $1 \mu \mathrm{g} / \mathrm{ml}$ puromycin. H9 ES cells were obtained from WiCell (WA09) and have been approved for these studies by the UKSCB Steering Committee. Human ES cells were maintained in culture with StemFlex culture media (Gibco A3349401) on growth factor reduced Matrigel coated dishes (Corning).

Vectors for viral production were: pCRV-1 for HIV-1 Gag/Pol (Naldini et al., 1996), and CSGW for GFP expression (Zennou et al., 2004). Lentiviral packaging plasmid PMDG2, which encodes VSV-G envelope, was used to pseudotype infectious virions (Addgene plasmid \# 12259). pCAGGS-Spike $\Delta \mathrm{c} 19$ was generated from pCAGGSSpike by digesting the vector backbone with EcoR1 and Nhel and subsequently gel purified. Q5 polymerase (NEB) was used to amplify the spike protein fragment using the $3^{\prime}$ primer to make a C-terminal
19 amino acid deletion. Primers with a 15bp overlap with the vector backbone were used. After PCR, the fragments were treated with Dpn1 for $1 \mathrm{~h}$ and subsequently gel purified. The fragment was then inserted into the vector using In-Fusion assembly (Takara Inc.). The plasmid was checked by sequencing.

For the generation of ACE2 over-expressing HEK 293T cells, the human ACE2 ORF was PCR amplified from Addgene plasmid 1786 and C-terminally fused with the porcine teschovirus-1-derived P2A cleavage sequence (ATNFSLLKQAGDVEENPGP) followed by the blasticidin resistance gene. This continuous, single ORF expression cassette was transferred into pLenti6-Dest_Puro by gateway recombination. Lenti-viral particles were generated by cotransfection of HEK 293T cells with pLenti6-Dest_Puro_ACE2-2ABla, pCMVR8.74 (Addgene plasmid 22036) and pMD2.G (Addgene plasmid 12259) using PEl. Supernatant containing virus particles was harvested after 48 h, 0.45 um filtered, and used to infect naive HEK 293T cells. Transduced cells stably expressing ACE2 were selected with $5 \mathrm{ug} / \mathrm{ml}$ blasticidin.

\section{Preparation of viruses}

Replication deficient VSV-G or SARS Cov2 pseudotyped HIV-1 virions were produced in HEK293T cells by transfection with pMDG2 or pCAGGS-Spike $\triangle \mathrm{c} 19$, pCRV GagPol and CSGW as described previously (Price et al., 2014). Viral supernatants were filtered through a $0.45 \mu \mathrm{m}$ membrane at 48 hours post-transfection and pelleted through a $20 \%$ sucrose cushion for $2 \mathrm{hrs}$ at $28 \mathrm{~K}$. Pelleted virions were drained and then resuspended in DMEM. Viral stocks were quantified by qRT-PCR as described previously (Vermeire and Verhasselt, 2013) with modifications. In brief, $5 \mu$ l of virus stock was mixed with $5 \mu$ lysis buffer $(0.25 \%$ Triton X-100, $50 \mathrm{mM} \mathrm{KCl}, 100 \mathrm{mM}$ Tris- $\mathrm{HCl}$ ( $\mathrm{pH}$ 7.4), 40\% glycerol, $0.1 \mu \mathrm{l}$ RNase Inhibitor). After incubation at room temp for $10 \mathrm{mins}, 90 \mu$ nuclease-free water was added. $2 \mu$ l of lysate was mixed with $5 \mu$ l TaqMan Fast Universal PCR Mix, $0.1 \mu \mathrm{l}$ MS2 RNA, $0.05 \mu \mathrm{l}$ RNase Inhibitor and $0.5 \mu \mathrm{l}$ MS2 primer/probe mix $(7.5 \mu \mathrm{M}$ primers Fwd: AACATGCTCGAGGGCCTT,

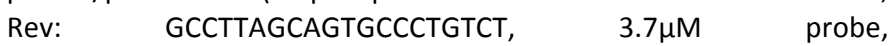
TGGGATGCTCCTACATG), in a final volume of $10 \mu \mathrm{l}$.

For titer determination of pseudotyped viruses, 293T ACE2 cells were plated into 96 well plates at a density of $7.5 \times 10^{3}$ cells per well and allowed to attach overnight. Viral stocks were titrated in triplicate by addition of virus onto cells. Infection was measured through GFP expression measured by visualisation on an Incucyte Live cell imaging system (Sartorius). Infection was enumerated as GFP positive cell area.

Live SARS-CoV-2 (SARS-CoV-2/human/Liverpool/REMRQ0001/2020) used in this study was isolated by Lance Turtle (University of Liverpool), David Matthews and Andrew Davidson (University of Bristol). SARS-CoV-2 stock was prepared in Vero hACE2-TMPRSS2 cells by infecting monolayer of cells with $0.01 \mathrm{MOI}$ of virus. Virus stock was harvested after 3 days by three freeze-thaw cycles and 5 $\min 300 x \mathrm{x}$ spin to remove cell debris. Virus titers were assessed by plaque assays in Vero ACE2/TMPRSS2 cells. For plaque assays, Vero hAce2-TMPRSS2 cells were seeded on 12-well dishes day prior infection. Next day serial dilutions of the supernatant (-1 to -6$)$ were prepared and used to infect cells for $1 \mathrm{~h}$ and then overlayed with $0.05 \%$ agarose in $2 \%$ FBS DMEM. After 3 days monolayers were fixed with $4 \%$ formaldehyde and the plaques were revealed with $0.1 \%$ toluidine blue staining. 


\section{Cerebral and ChP organoid culture condition}

Cerebral organoids were prepared from single cell suspension of human ES cells as previously described (Lancaster and Knoblich, 2014) and cultured with Stem Cell Technologies Cerebral Organoid kit (catalogue n. 08570, 08571). Briefly, EBs were generated by seeding 2000 cells in a 96-well U-bottom low attachment plate with EB media and $50 \mu \mathrm{M}$ Y-27632 ROCK inhibitor for 3 days. EB media was replaced on day 5 with $\mathrm{NI}$ media in the same 96 well plate. At day 7 , EBs were embedded in $30 \mu \mathrm{l}$ Matrigel (Corning) using sheets of dimpled parafilm and incubated for $20 \mathrm{~min}$ at $37^{\circ} \mathrm{C}$ as previously detailed (Lancaster and Knoblich, 2014). EBs were then transferred to a 6-well plate in $3 \mathrm{ml}$ of Expansion media per well. From day 30, dissolved Matrigel (1:50) was added to the Maturation media.

Air-Liquid Interface Cerebral Organoid (ALI-CO) culture was performed as previously described (Giandomenico et al., 2019). Briefly, mature organoids (day 55) were collected, washed in HBSS without $\mathrm{Ca} 2+$ and $\mathrm{Mg} 2+$ and embedded in 3\% low-gellingtemperature agarose (Sigma, A9414) at $40^{\circ} \mathrm{C}$ in embedding molds (Sigma, E6032). Agarose blocks were then incubated for $10-15 \mathrm{~min}$ on ice and sectioned using a vibratome (Leica VT100S vibrating microtome) in cold HBSS. Sections ( $300 \mu \mathrm{m}$-thick) were collected onto Millicell CM culture inserts (Millipore, PICMORG50) in 6-well plates and left at $37^{\circ} \mathrm{C}$ for $1 \mathrm{~h}$ to equilibrate with serum-supplemented slice culture media (SSSCM). SSSCM was then replaced with serum-free slice culture media (SFSCM). ALI-CO cultures were fed with SFSCM daily.

\section{Single-cell RNA-seq and in vivo expression analyses}

scRNA-seq data was previously published (Pellegrini et al., 2020) and was analysed using the Seurat v3 R package. The already normalized and scaled matrix was visualized by UMAP dimensionality reduction. Subclustering of ChP cell types was performed by first extracting and combining cells of the ChP mature epithelial, immature/hem, and stromal clusters, followed by FindNeighbors, FindClusters and UMAP dimensionality reduction on PCS 1-12 (as determined by ElbowPlot). For expression correlation analysis, pearson correlation was performed between ACE2 expression in all ChP cells and all other genes. The top 20 correlated genes were used for GO term enrichment analysis using gProfiler (Reimand et al., 2011).

In vivo data were obtained from the Allen Human Brain Atlas (http://human.brain-map.org/). Z-scaled data were downloaded for the two ACE2 probes available for all samples and brain regions. Mean Z-score was calculated for all samples within each brain region for each probe.

\section{Organoid infection experiments}

Organoid infections were performed by addition of virus to the culture medium at an expected $\mathrm{MOI}$ of 0.5 for each virus based on viral titre determined in 293T ACE2 cells (in the case of pseudotyped virus) or plaque assay (in the case of live SARS-CoV-2). To calculate an $\mathrm{MOI}$, counts from previous single cell dissociations (Pellegrini et al., 2020) were used to estimate cell numbers in organoids. Thus, $7 \times 10^{3}$ PFU virus was added to choroid plexus tissues with an estimated number of 17,000 cells to achieve $\mathrm{MOI} 0.5$. For mixed identity or pure cortical organoids, with an increased cell number estimated at approximately 35,000 cells, we used $1.4 \times 10^{4}$ PFU virus, or $1.4 \times 10^{5}$ in experiments using 10 -fold increased viral quantity. In the case of organoid ChP tissue, ChP epithelium was physically separated from the organoid and broken into three large pieces before infection, and SARS-CoV-2 virus or pseudovirions, negative control, or positive control was added to each of the three pieces. This provided an added internal control so that the experiment and control conditions were tested on tissues obtained from the exact same organoid.

\section{qRT-PCR analysis of viral replication}

RNA extractions from $140 \mu$ l of inoculated culture medium were performed using the Qiagen QIAmp Viral RNA mini kit and eluted in $80 \mu \mathrm{l}$ of AVE elution buffer. $5 \mu \mathrm{l}$ of extract were used per $20 \mu \mathrm{l}$ RT-qPCR reaction. Reaction mixes were set up according to the manufacturer's instructions with the addition of a CDC-N1 SARS-CoV2 probe/primer mix (IDT 2019-nCoV RUO kit) with a final concentration of $500 \mathrm{nM}$ for each primer and $125 \mathrm{nM}$ of the hydrolysis probe. One-step RT-qPCR reactions were run on a Viia7s real-time qPCR instrument with the following parameters: $1.55^{\circ} \mathrm{C}$ for 10 minutes for reverse transcription $2.95^{\circ} \mathrm{C}$ for 1 minute for enzyme activation. 3. 45 cycles of 10 seconds denaturation at $95^{\circ} \mathrm{C}$ and 30 seconds annealing/extension at $55^{\circ} \mathrm{C}$. Fluorescence was recorded at the end of the extension step. To estimate viral copies per reaction, a dilution series of $\mathrm{nCoV}-2019 \mathrm{~N}$-gene positive control (IDT) was performed in technical duplicates. Sample $\mathrm{Cq}$ values were then converted to viral copies per reaction using the standard curve's linear regression model. Values in dot plots represent $\log 10$ transformed copies per reaction of individual biological samples over time. For samples where no virus was detected, a pseudo value of 0 was assigned to represent the data point on the graph. Raw data is available upon request.

\section{Immunostaining and confocal imaging}

Organoids were fixed in $4 \%$ PFA overnight at $4^{\circ} \mathrm{C}$ and then moved to $30 \%$ sucrose buffer at $4^{\circ} \mathrm{C}$ for at least $24 \mathrm{~h}$. Organoids were then embedded in gelatin and sectioned as previously described (Lancaster and Knoblich, 2014). After blocking and permeabilisation with $0.25 \%$ Triton and $1 \%$ donkey serum buffer, sections were incubated overnight with the following primary antibodies according to their optimized instruction: sheep anti-TTR (1:500, Abcam, ab9015), rabbit anti-ACE2 (1:100, Abcam, ab108209), goat anti-ACE2 (1:100, R\&D Systems, AF933), rabbit anti-HTR2C (1:500, Abcam, ab133570), mouse anti-TMPRSS2 (with antigen retrieval, 1:50, SantaCruz, Sc515727), rabbit anti-claudin 5 (1:200, ThermoFisher, 341600), rabbit anti-Sox2 (1:300, Abcam, ab97959), rabbit anti-APOA1 (1:100, ThermoFisher, PA5-88109), sheep anti-Tbr2 (1:200, R\&D Systems, AF6166), rat anti-CTIP2 (1:300, Abcam, ab18465), mouse anti-HuC/D (1:500, LifeTech, A21271), rabbit anti-DLK1 (1:200, Abcam, ab21682), rabbit anti-GFAP antibody (1:200, Abcam, ab7260), chicken anti-MAP2 (1:1000, Abcam, ab5392),_chicken antiGFP (1:500, Abcam, ab13970), goat anti-MSX1 (1:200, R\&D, AF5045), rabbit anti-ND2 (1:500, Abcam, ab104430), mouse anti-SMI312 (1:500, Biolegend, 837934), mouse anti-SARS-CoV-2 spike glycoprotein (1:200, GeneTex, GTX632604), rabbit anti-SARS-CoV-2 spike glycoprotein C-terminal (1:200, Abcam, ab252690). To mark the nuclei, Dapi $(1: 1000)$ was used added with the secondary antibody incubation. Secondary antibodies labelled with Alexa 488, 568 and 647 were applied $1 \mathrm{~h}$ at room temperature. Incubation with 
HCS LipidTox (1:1000 in PBS, Thermo Fisher, H34477) was carrier for $20 \mathrm{~min}$ after secondary antibody to visualize lipid droplets. Slides were then washed in PBS and mounted using Prolong Diamond mounting media. All the staining steps for ALI-COs were carried out in permeabilisation buffer and their duration was extended as previously described (Giandomenico et al., 2019).

Images were acquired using a Zeiss LSM 780 confocal microscope (Carl Zeiss) and prepared using Fiji (NIH). The Fiji Huttner plugin was used for the quantification of GFP-positive cells over total cells: 100 Dapi-stained nuclei were counted in each experiment and number of GFP-positive cells over total cells counted was then recorded.

\section{Immunoblotting}

For immunoblotting, organoids were snap-frozen in liquid nitrogen and homogenized in RIPA buffer with protease inhibitors (Roche) to produce total protein lysate. Protein samples were prepared using NuPAGE LDS Sample Buffer $4 \mathrm{x}$ and DTT $1 \mathrm{M}$ and heated at $95^{\circ} \mathrm{C}$ for $15 \mathrm{~min}$. Protein samples and ladder were loaded into a polyacrylamide gel and run for $2 \mathrm{~h}$ at $100 \mathrm{mV}$. Wet transfer in PDVF membrane (Immobilion) was carried out for $3 \mathrm{~h}$ or overnight at $4^{\circ} \mathrm{C}$. Membranes were blocked in $5 \%$ milk in PBS-T and incubated overnight at $4^{\circ} \mathrm{C}$ with primary antibodies (rabbit anti-ACE2 and mouse anti- $\beta$-actin). After 3 washes in PBS-T, secondary antibodies Alexafluor conjugated were added for $1 \mathrm{~h}$ at room temperature and membranes were images using a Li-COR Odyssey CLx Infrared Imaging System.

\section{Author contributions}

L.P. designed and conducted experiments, analysed data, and wrote the manuscript. A.A. performed viral experiments and collected samples. D.L.M. prepared and analysed pseudoviruses. M.J.K. performed RT-qPCR analyses. D.P. generated reagents for cell line generation. A.P.C. generated reagents and cloning constructs. L.C.J. designed and supervised viral work. M.A.L. designed and supervised the project, analysed data, and wrote the manuscript.

\section{Acknowledgments}

The authors would like to thank members of the Lancaster lab for helpful feedback and discussions. We also thank G. Papa for cell lines used in these studies. We also thank the Light Microscopy and BSL3 facilities of the MRC Laboratory of Molecular Biology. This work was supported by the Medical Research Council (MC_UP_1201/9).

\section{Declaration of interests}

The authors have filed a patent based on ChP organoids.

\section{Data and materials availability}

Single cell sequencing data were previously published and accessible on NCBI GEO, accession number GSE150903, and through the UCSC cell browser. Raw data is available upon request. H9 (WA09) cells are available through MTA with WiCell.

\section{References}

Aizawa, Y., Seki, N., Nagano, T., and Abe, H. (2015). Chronic hepatitis $C$ virus infection and lipoprotein metabolism. World J. Gastroenterol. 21, 10299-10313.
Besler, C., Lüscher, T.F., and Landmesser, U. (2012). Molecular mechanisms of vascular effects of High-density lipoprotein: Alterations in cardiovascular disease. EMBO Mol. Med. 4, 251-268.

Cantuti-Castelvetri, L., Ohja, R., Pedro, L., Djannatian, M., Franz, J., Kuivanen, S., Kallio, K., Kaya, T., Anastasina, M., Smura, T., et al. (2020). Neuropilin-1 facilitates SARS-CoV-2 cell entry and provides a possible pathway into the central nervous system. BioRxiv 2020.06.07.137802.

Chen, R., Wang, K., Yu, J., Chen, Z., Wen, C., and Xu, Z. (2020). The spatial and cell-type distribution of SARS-CoV-2 receptor ACE2 in human and mouse brain. BioRxiv.

Daly, J.L., Simonetti, B., Antón-plágaro, C., Kavanagh, M., Shoemark, D.K., Simón-gracia, L., Klein, K., Hollandi, R., Greber, U.F., Horvath, P., et al. (2020). Neuropilin-1 is a host factor for SARS-CoV-2 infection. BioRxiv.

Dani, N., Herbst, R.H., Habib, N., Head, J., Dionne, D., Nguyen, L., McCabe, C., Cui, J., Shipley, F.B., Jang, A., et al. (2019). A cellular and spatial map of the choroid plexus across brain ventricles and ages. BioRxiv.

Fame, R.M., and Lehtinen, M.K. (2020). Emergence and Developmental Roles of the Cerebrospinal Fluid System. Dev. Cell 52, 261-275.

Fultz, N.E., Bonmassar, G., Setsompop, K., Stickgold, R.A., Rosen, B.R., Polimeni, J.R., and Lewis, L.D. (2019). Coupled electrophysiological, hemodynamic, and cerebrospinal fluid oscillations in human sleep. Science (80-. ). 366, 628-631.

Ghersi-Egea, J.F., Strazielle, N., Catala, M., Silva-Vargas, V., Doetsch, F., and Engelhardt, B. (2018). Molecular anatomy and functions of the choroidal blood-cerebrospinal fluid barrier in health and disease. Acta Neuropathol. 135, 337-361.

Giandomenico, S.L., Mierau, S.B., Gibbons, G.M., Wenger, L.M.D., Masullo, L., Sit, T., Sutcliffe, M., Boulanger, J., Tripodi, M., Derivery, E., et al. (2019). Cerebral organoids at the air-liquid interface generate diverse nerve tracts with functional output. Nat. Neurosci. 22, 669-679.

Giroglou, T., Cinatl, J., Rabenau, H., Drosten, C., Schwalbe, H., Doerr, H.W., and von Laer, D. (2004). Retroviral Vectors Pseudotyped with Severe Acute Respiratory Syndrome Coronavirus S Protein. J. Virol. 78, 9007-9015.

Grassi, G., Caprio, G. Di, Fimia, G.M., Ippolito, G., Tripodi, M., Alonzi, T., Grassi, G., Caprio, G. Di, Fimia, G.M., Ippolito, G., et al. (2016). Hepatitis C virus relies on lipoproteins for its life cycle. World J. Gastroenterol. 22, 1953-1965.

Hawrylycz, M.J., Lein, E.S., Guillozet-Bongaarts, A.L., Shen, E.H., Ng, L., Miller, J.A., Van De Lagemaat, L.N., Smith, K.A., Ebbert, A., Riley, Z.L., et al. (2012). An anatomically comprehensive atlas of the adult human brain transcriptome. Nature 489, 391-399.

Hoffmann, M., Kleine-weber, H., Schroeder, S., Krüger, N., Herrler, T., Erichsen, S., Schiergens, T.S., Herrler, G., Wu, N.-H., Nitsche, A., et al. (2020a). SARS-CoV-2 Cell Entry Depends on ACE2 and TMPRSS2 and Is Blocked by a Clinically Proven Protease Inhibitor. Cell 181, 271280.

Hoffmann, M., Kleine-Weber, H., and Pöhlmann, S. (2020b). Multibasic Cleavage Site in the Spike Protein of SARS-CoV-2 Is Essential for Infection of Human Lung Cells. Mol. Cell 78, 779-784.

Ko, C.W., Qu, J., Black, D.D., and Tso, P. (2020). Regulation of intestinal lipid metabolism: current concepts and relevance to disease. Nat. Rev. Gastroenterol. Hepatol. 17, 169-183. Lamers, M.M., Beumer, J., Vaart, J. van der, Knoops, K., Puschhof, J., Breugem, T.I., Ravelli, R.B.G., Schayck, J.P. van, Mykytyn, A.Z., Duimel, H.Q., et al. (2020). SARS-CoV-2 productively infects human 
gut enterocytes. Science (80-. ). 1669, 1-11.

Lancaster, M., and Knoblich, J.A. (2014). Generation of cerebral organoids from human pluripotent stem cells. Nat. Protoc. 9, 23292340.

Lancaster, M., Corsini, N.S., Wolfinger, S., Gustafson, E.H., Phillips, A.W., Burkard, T.R., Otani, T., Livesey, F.J., and Knoblich, J.A. (2017). Guided self-organization and cortical plate formation in human brain organoids. Nat. Publ. Gr.

Lancaster, M.A., Renner, M., Martin, C.-A., Wenzel, D., Bicknell, L.S., Hurles, M.E., Homfray, T., Penninger, J.M., Jackson, A.P., and Knoblich, J.A. (2013). Cerebral organoids model human brain development and microcephaly. Nature 501, 373-379.

Lehtinen, M.K., and Walsh, C.A. (2011). Neurogenesis at the Brain Cerebrospinal Fluid Interface. Annu. Rev. Cell Dev. Biol. 653-682.

Lehtinen, M.K., Zappaterra, M.W., Chen, X., Yang, Y.J., Hill, A.D., Lun, M., Maynard, T., Gonzalez, D., Kim, S., Ye, P., et al. (2011). The Cerebrospinal Fluid Provides a Proliferative Niche for Neural Progenitor Cells. Neuron 69, 893-905.

Lun, M.P., Monuki, E.S., and Lehtinen, M.K. (2015a). Development and functions of the choroid plexus-cerebrospinal fluid system. Nat. Rev. Neurosci. 16, 445-457.

Lun, M.P., Johnson, M.B., Broadbelt, K.G., Watanabe, M., Kang, Y. -j., Chau, K.F., Springel, M.W., Malesz, A., Sousa, A.M.M., Pletikos, M., et al. (2015b). Spatially Heterogeneous Choroid Plexus Transcriptomes Encode Positional Identity and Contribute to Regional CSF Production. J. Neurosci. 35, 4903-4916.

Miller, J.A., Guillozet-bongaarts, A., Gibbons, L.E., Postupna, N., Renz, A., Beller, A.E., Sunkin, S.M., Ng, L., Rose, S.E., Smith, K.A., et al. (2017). Neuropathological and transcriptomic characteristics of the aged brain. Elife 1-26.

Moldofsky, H., and Patcai, J. (2011). Chronic widespread musculoskeletal pain, fatigue, depression and disordered sleep in chronic post-SARS syndrome; a case-controlled study. BMC Neurol. 11, 2-7.

Montalvan, V., Lee, J., Bueso, T., Toledo, J. De, and Rivas, K. (2020). Neurological manifestations of COVID-19 and other coronavirus infections: A systematic review. Clin. Neurol. Neurosurg. 194, 105921.

Moriguchi, T., Harii, N., Goto, J., Harada, D., Sugawara, H., Takaminoa, J., Uenoa, M., Sakataa, H., Kondoa, K., Myosea, N., et al. (2020). A first case of meningitis/encephalitis associated with SARSCoronavirus-2. Int. J. Infect. Dis. 94, 55-58.

Naldini, L., Blomer, U., Gallay, P., Ory, D., Mulligan, R., Gage, F.H., Verma, I.M., and Trono, D. (1996). In Vivo Gene Delivery and Stable Transduction of Nondividing Cells by a Lentiviral Vector. Science (80-. ). 272, 263-267.

Natelson, B.H., Weaver, S.A., Tseng, C., and Ottenweller, J.E. (2005). Spinal Fluid Abnormalities in Patients with Chronic Fatigue Syndrome. Clin. Diagn. Lab. Immunol. 12, 52-55.

Olsson, M., Ärlig, J., Hedner, J., Blennow, K., and Zetterberg, H. (2018). Sleep deprivation and cerebrospinal fluid biomarkers for Alzheimer' s disease. Sleep Res. Soc. 1-8.

Ou, X., Liu, Y., Lei, X., Li, P., Mi, D., Ren, L., Guo, L., Guo, R., Chen, T., $\mathrm{Hu}$, J., et al. (2020). Characterization of spike glycoprotein of SARSCoV-2 on virus entry and its immune cross-reactivity with SARS-CoV. Nat. Commun. 11.

Papa, G., Mallery, D.L., Albecka, A., Welch, L., Cattin-ortolá, J., Paul, D., Mcmahon, H., Goodfellow, I.G., Carter, A., Munro, S., et al. (2020). Furin cleavage of SARS-CoV-2 Spike promotes but is not essential for infection and cell-cell fusion.

Payne, B.A.I., Hateley, C.L., Ong, E.L.C., Premchand, N., Schmid, M.L.,
Schwab, U., Newton, J.L., and Price, D.A. (2013). HIV-associated fatigue in the era of highly active antiretroviral therapy: Novel biological mechanisms? HIV Med. 14, 247-251.

Pellegrini, L., Bonfio, C., Chadwick, J., Begum, F., Skehel, M., and Lancaster, M.A. (2020). Human CNS barrier-forming organoids with cerebrospinal fluid production. Science (80-. ). 5626, 1-21.

Poynard, T., Cacoub, P., Ratziu, V., Myers, R.P., Dezailles, M.H., Mercadier, A., Ghillani, P., Charlotte, F., Piette, J.C., and Moussalli, J. (2002). Fatigue in patients with chronic hepatitis C. J. Viral Hepat. 9, 295-303.

Price, A.J., Jacques, D.A., Mcewan, W.A., Fletcher, A.J., Essig, S., Chin, J.W., Halambage, U.D., Aiken, C., and James, L.C. (2014). Host Cofactors and Pharmacologic Ligands Share an Essential Interface in HIV-1 Capsid That Is Lost upon Disassembly. PLOS Pathog. 10, e1004459.

Qi, F., Qian, S., Zhang, S., and Zhang, Z. (2020). Single cell RNA sequencing of 13 human tissues identify cell types and receptors of human coronaviruses. Biochem. Biophys. Res. Commun. 526, 135140.

Qian, X., Nguyen, H.N., Jacob, F., Song, H., and Ming, G. (2017). Using brain organoids to understand Zika virus-induced microcephaly. Development 144, 952-957.

Ramani, A., Müller, L., Ostermann, P.N., Gabriel, E., Abida-Islam, P., Müller-Schiffmann, A., Mariappan, A., Goureau, O., Gruell, H., Walker, A., et al. (2020). SARS-CoV-2 targets cortical neurons of 3D human brain organoids and shows neurodegeneration-like effects. BioRxiv (Preprint) 2020.05.20.106575.

Ransohoff, R.M., and Engelhardt, B. (2012). The anatomical and cellular basis of immune surveillance in the central nervous system. Nat. Publ. Gr. 12, 623-635.

Rasa, S., Nora-Krukle, Z., Henning, N., Eliassen, E., Shikova, E., Harrer, T., Scheibenbogen, C., Murovska, M., and Prusty, B.K. (2018). Chronic viral infections in myalgic encephalomyelitis/chronic fatigue syndrome (ME/CFS). J. Transl. Med. 16, 1-25.

Redzic, Z. (2011). Molecular biology of the blood-brain and the blood-cerebrospinal fluid barriers: Similarities and differences. Fluids Barriers CNS 8, 3.

Reimand, J., Arak, T., and Vilo, J. (2011). G:Profiler - A web server for functional interpretation of gene lists (2011 update). Nucleic Acids Res. 39, 307-315.

Schaller, T., Hirschbühl, K., Burkhardt, K., Braun, G., Trepel, M., Märkl, B., and Claus, R. (2020). Postmortem Examination of Patients with COVID-19. JAMA - J. Am. Med. Assoc. 323, 2518-2520.

Schwerk, C., Tenenbaum, T., Kim, K.S., and Schroten, H. (2015). The choroid plexus - a multi-role player during infectious diseases of the CNS. Front. Cell. Neurosci. 9, 1-11.

Song, E., Zhang, C., Israelow, B., Lu, P., Weizman, O., Liu, F., Dai, Y., Szigeti-buck, K., Yasumoto, Y., Wang, G., et al. (2020). Neuroinvasive potential of SARS-CoV-2 revealed in a human brain organoid model. BioRxiv.

Strazielle, N., and Ghersi-Egea, J.F. (2013). Physiology of blood-brain interfaces in relation to brain disposition of small compounds and macromolecules. Mol. Pharm. 10, 1473-1491.

Sungnak, W., Huang, N., Bécavin, C., Berg, M., Queen, R., Litvinukova, M., Talavera-lópez, C., Maatz, H., Reichart, D., Sampaziotis, F., et al. (2020). SARS-CoV-2 entry factors are highly expressed in nasal epithelial cells together with innate immune genes. Nat. Med. 26.

Vermeire, J., and Verhasselt, B. (2013). Quantification of Retro- and Lentiviral Reverse Transcriptase Activity by Real-time PCR. BioProtocol 3, e780.

Walls, A.C., Park, Y., Tortorici, M.A., Wall, A., Mcguire, A.T., Veesler, 
D., Walls, A.C., Park, Y., Tortorici, M.A., Wall, A., et al. (2020). Structure, Function, and Antigenicity of the SARS-CoV-2 Spike Glycoprotein. Cell 181, 281-292.e6.

Wang, H., Li, X., Li, T., Zhang, S., Wang, L., Wu, X., and Liu, J. (2020). The genetic sequence, origin, and diagnosis of SARS-CoV-2. Eur. J. Clin. Microbiol. Infect. Dis.

Wang, Z., Wang, L., Zhang, Z., Feng, L., Song, X., and Wu, J. (2019). Apolipoprotein A-IV involves in glucose and lipid metabolism of rat. Nutr. Metab. 16, 1-9.

Williams, M. V, Cox, B., Lafuse, W.P., and Ariza, M.E. (2019). EpsteinBarr virus dUTPase induces neuroinflammatory mediators: Implications for Myalgic Encephalomyelitis/Chronic Fatigue Syndrome. Clin Ther. 41, 848-863.

Wrapp, D., Wang, N., Corbett, K.S., Goldsmith, J.A., Hsieh, C., Abiona, O., Graham, B.S., and Mclellan, J.S. (2020). Cryo-EM structure of the 2019-nCoV spike in the prefusion conformation. Science (80-. ). 1263, 1260-1263.

Wrensch, F., Crouchet, E., Ligat, G., Zeisel, M.B., Keck, Z.-Y., Foung, S.K.H., Schuster, C., and Baumert, T.F. (2018). Hepatitis C virus (HCV) - Apolipoprotein interactions and immune evasion and their impact on HCV vaccine design. Front. Immunol. 9, 1-9.
Wu, F., Zhao, S., Chen, Y.-M., Wang, W., Song, Z.-G., Hu, Y., Tao, Z.W., Tian, J.-H., Pei, Y.-Y., Yuan, M.-L., et al. (2020). A new coronavirus associated with human respiratory disease in China. Nature 579.

Yang, N., and Shen, H. (2020). Targeting the Endocytic Pathway and Autophagy Process as a Novel Therapeutic Strategy in COVID-19. Int. J. Biol. Sci. 16, 1724-1731.

Zang, R., Gomez Castro, M.F., McCune, B.T., Zeng, Q., Rothlauf, P.W., Sonnek, N.M., Liu, Z., Brulois, K.F., Wang, X., Greenberg, H.B., et al. (2020). TMPRSS2 and TMPRSS4 promote SARS-CoV-2 infection of human small intestinal enterocytes. Sci. Immunol. 5.

Zennou, V., Perez-Caballero, D., Göttlinger, H., and Bieniasz, P.D. (2004). APOBEC3G Incorporation into Human Immunodeficiency Virus Type 1 Particles. J. Virol. 78, 12058-12061.

Zhou, T., Tan, L., Cederquist, G.Y., Fan, Y., Hartley, B.J., Mukherjee, S., Tomishima, M., Brennand, K.J., Zhang, Q., Schwartz, R.E., et al. (2017). High-Content Screening in hPSC-Neural Progenitors Identifies Drug Candidates that Inhibit Zika Virus Infection in Fetal-like Organoids and Adult Brain. Cell Stem Cell 21, 274-283.e5. 
bioRxiv preprint doi: https://doi.org/10.1101/2020.08.20.259937; this version posted August 21, 2020. The copyright holder for this preprint (which was not certified by peer review) is the author/funder, who has granted bioRxiv a license to display the preprint in perpetuity. It is made available under aCC-BY-ND 4.0 International license.

Supplementary Figures

\section{Supplemental Figure 1}

\section{A}

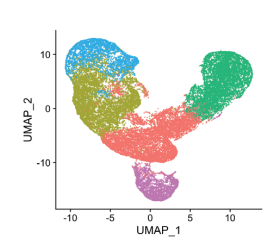

B
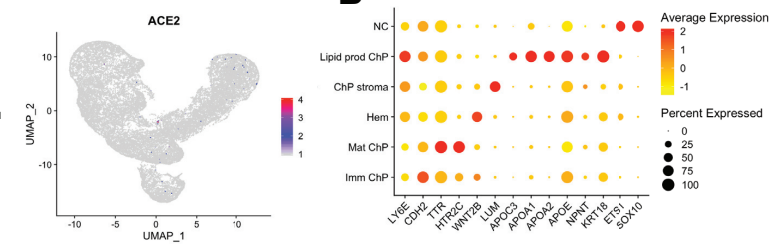
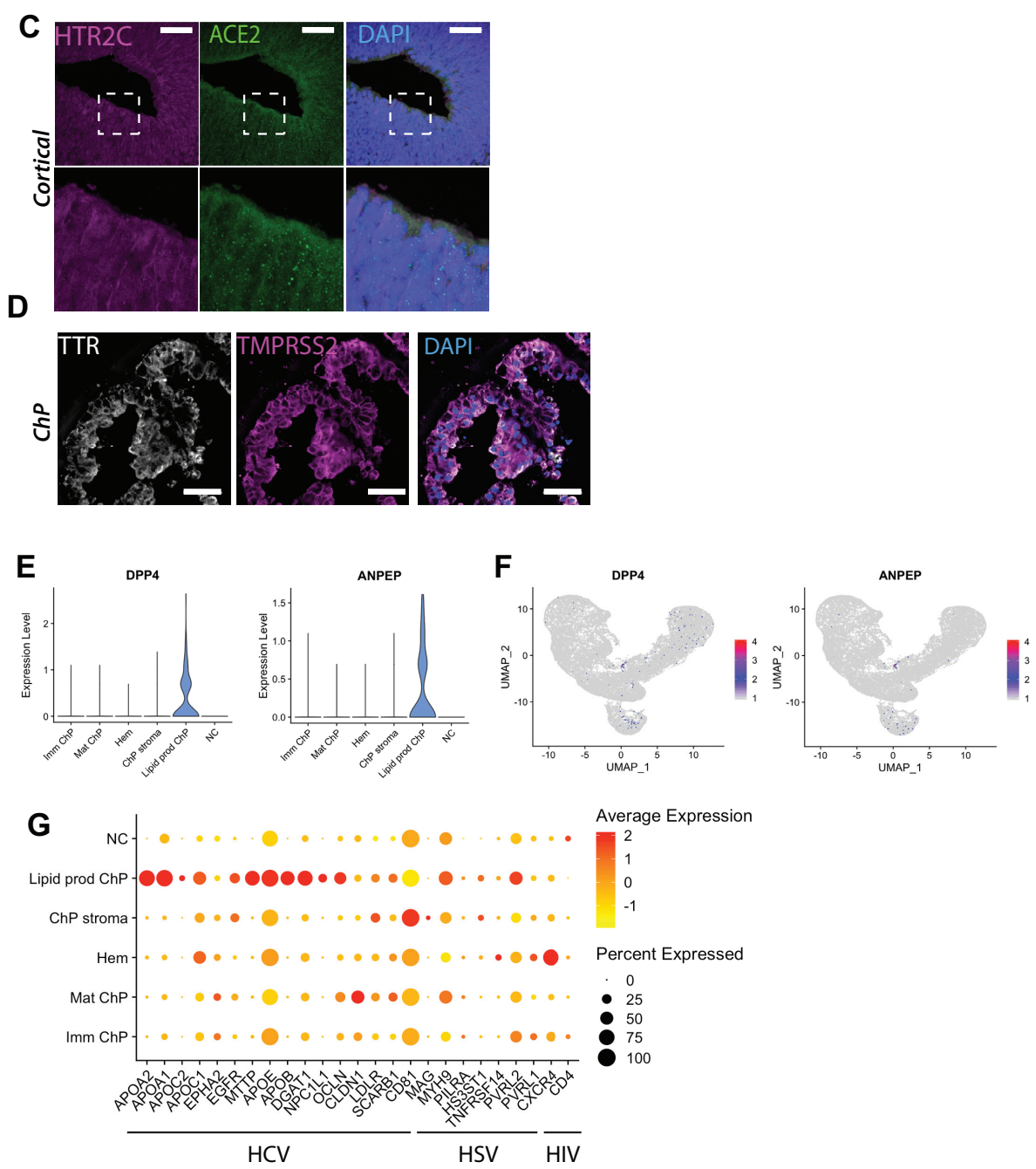

Supplementary Figure 1. (A) UMAP plot showing the main populations previously identified by scRNA-seq in cerebral and ChP organoids combined (Pellegrini et al., 2020) (left) and feature plot showing sparse expression of ACE2 in the ChP clusters (right). (B) Dot plot showing average expression and percentage of cells expressing top genes in the six main ChP subclusters identified by scRNA-seq. Lipid-producing ChP cells express apolipoprotein genes such as APOC3, APOA1, APOA2 and APOE as well as epithelial markers such as KRT18 (keratin 18) and lateral ventricle ChP marker LY6E (lymphocyte antigen 6E). (C) Representative confocal images of cortical lobe from an organoid with mixed identity immunostained for ChP marker HTR2C (magenta), ACE2 (green) and DAPI (blue). Scale bar: $50 \mu \mathrm{m}$. (D) Representative confocal images of a ChP epithelial region from a mixed identity organoid stained for ChP marker TTR (grey), TMPRSS2 (magenta) and DAPI (blue). Scale bar: $50 \mu \mathrm{m}$. (E) Violin plots showing expression levels of human coronavirus entry factors DPP4 and ANPEP in the lipid-producing ChP cell subcluster identified by scRNA-seq. (F) Feature plots showing expression of DPP4 and ANPEP in the ChP subpopulations identified by scRNA-seq analysis. (G) Dot plot showing average expression and percentage of cells expressing HCV viral entry factors in the six subclusters identified by scRNA-seq of ChP organoids. $\mathrm{ChP}$ lipid-producing cells show the highest expression of HCV viral entry factors as compared to the other subpopulations. 


\section{Supplemental Figure 2}

A

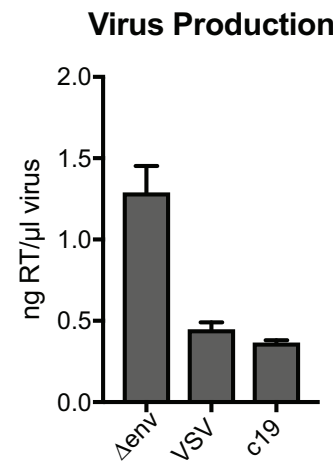

D
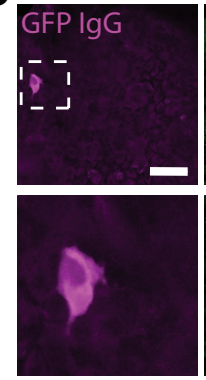

$\mathbf{F}$
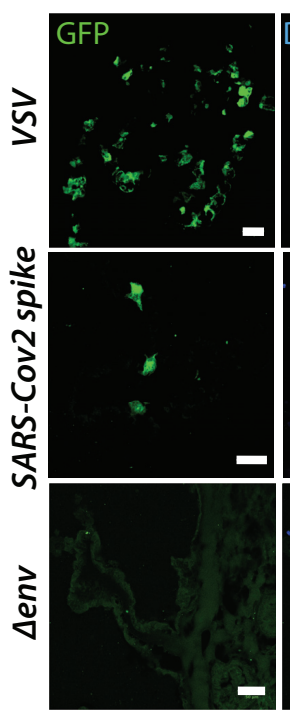

B

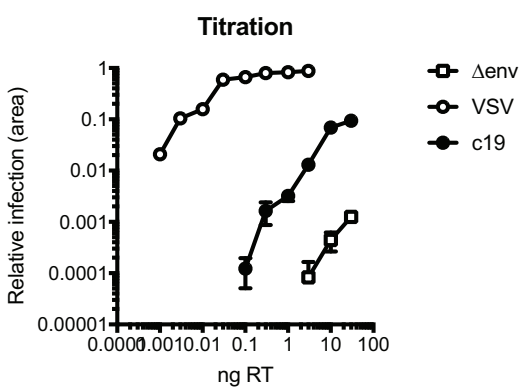

C

i.u. per ng RT

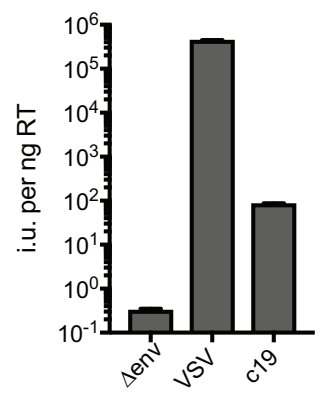

E
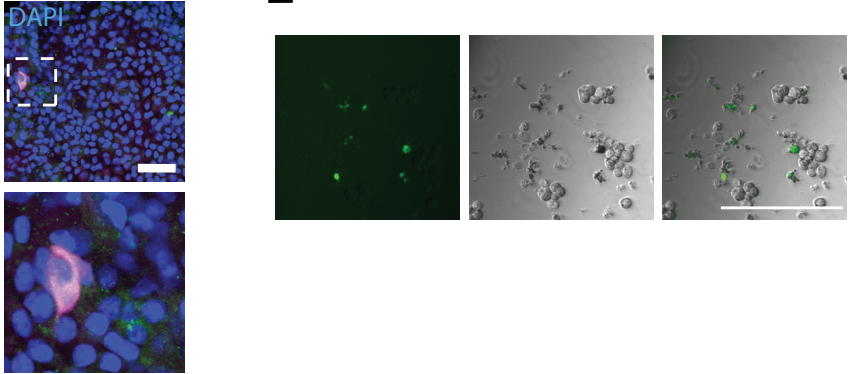

G

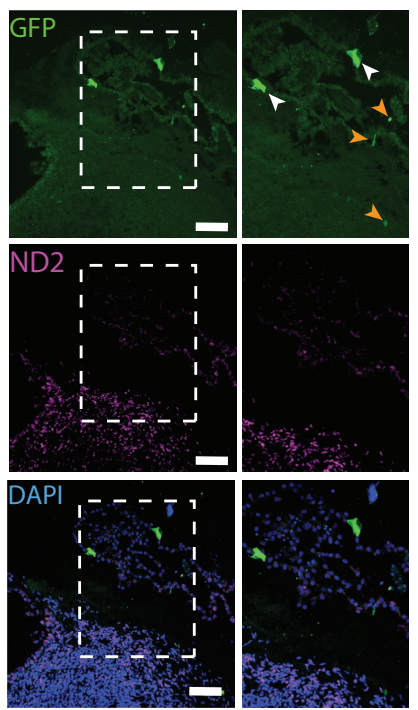

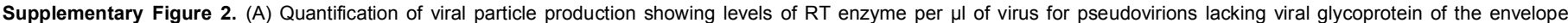

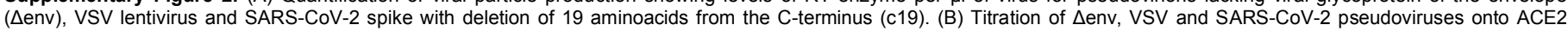

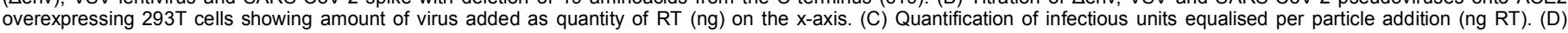

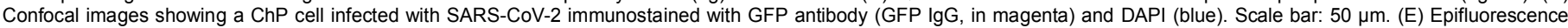

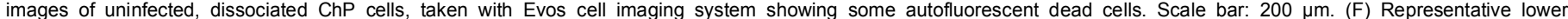

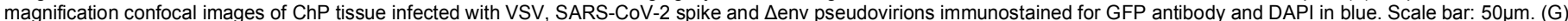

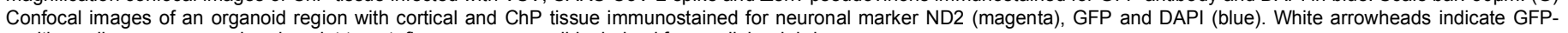
positive cells, orange arrowheads point to autofluorescence possibly derived from cellular debris. 
bioRxiv preprint doi: https://doi.org/10.1101/2020.08.20.259937; this version posted August 21, 2020. The copyright holder for this preprint (which was not certified by peer review) is the author/funder, who has granted bioRxiv a license to display the preprint in perpetuity. It is made available under aCC-BY-ND 4.0 International license.

\section{Supplemental Figure 3}
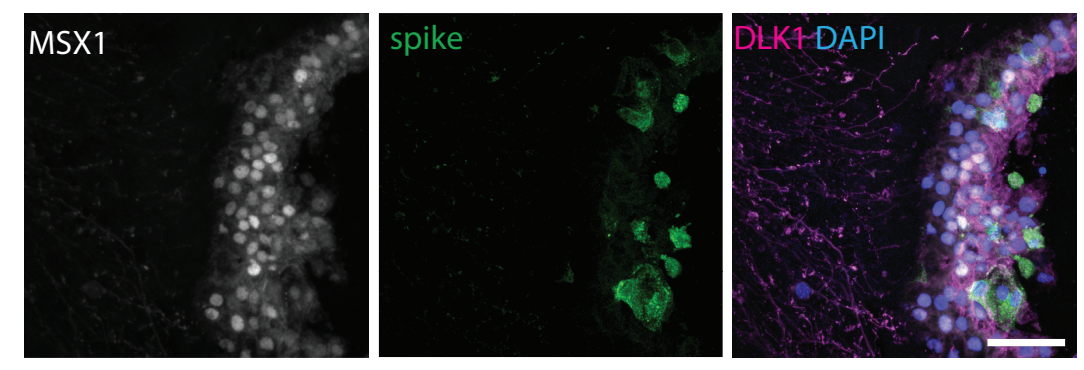

Supplementary Figure 3. Staining for viral spike protein and a marker of ChP stroma (DLK1) as well as ChP marker MSX1 showing no infection of stromal cells despite abundant infection of epithelium. Scale bar: $50 \mu \mathrm{m}$. 
bioRxiv preprint doi: https://doi.org/10.1101/2020.08.20.259937; this version posted August 21, 2020. The copyright holder for this preprint (which was not certified by peer review) is the author/funder, who has granted bioRxiv a license to display the preprint in perpetuity. It is made available under aCC-BY-ND 4.0 International license.

\section{Supplemental Figure 4}
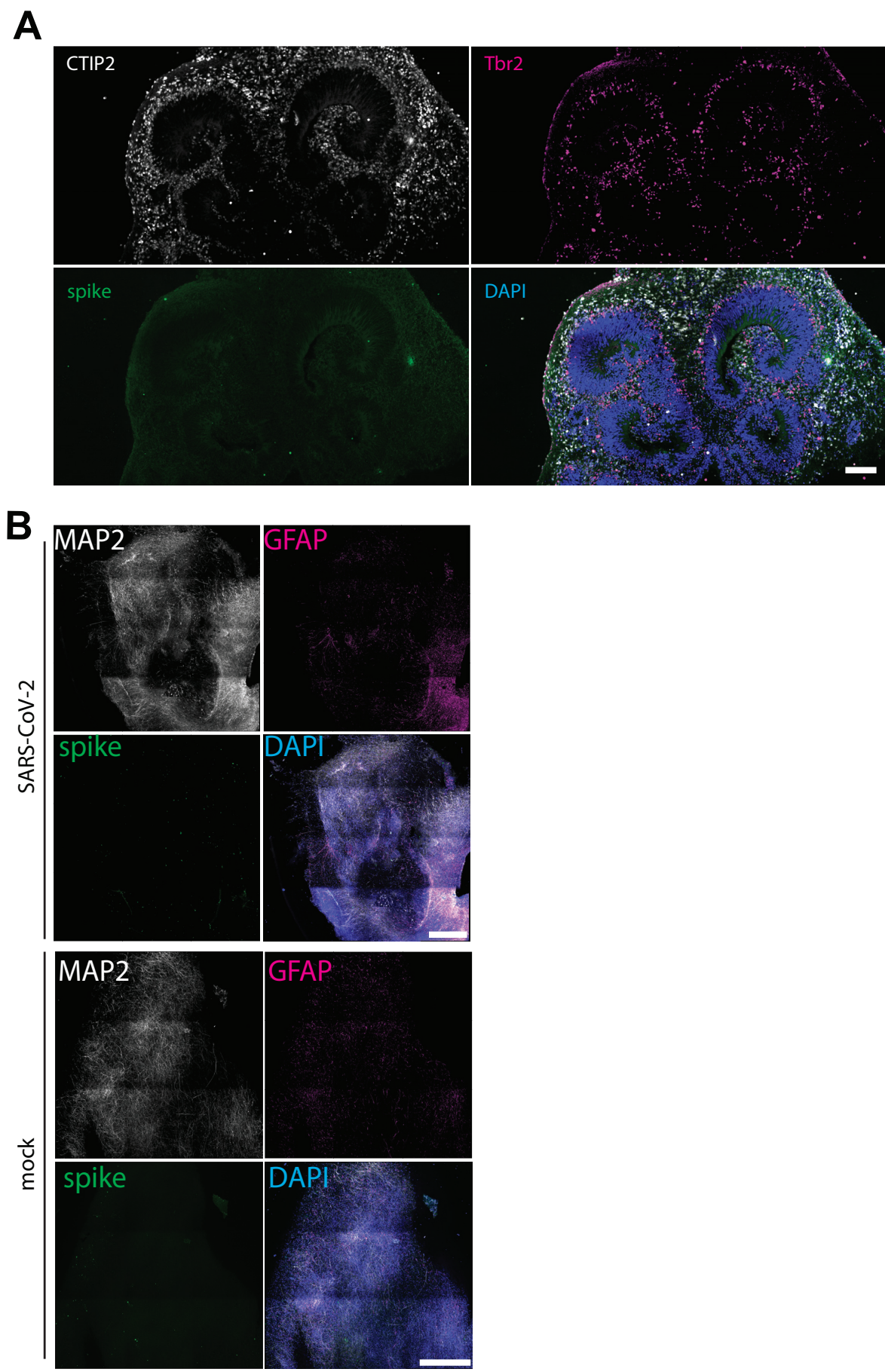

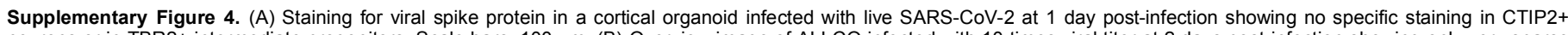

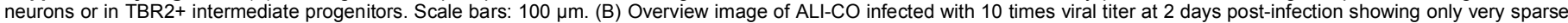
staining, despite abundant neurons (MAP2) and glia (GFAP). Scale bars: $500 \mu \mathrm{m}$ 